\title{
Sarcopenia: a chronic complication of type 2 diabetes mellitus
}

\author{
Heloísa Trierweiler', Gabrielle Kisielewicz , Thaísa Hoffmann Jonasson², Ricardo Rasmussen Petterle ${ }^{3}$, \\ Carolina Aguiar Moreira ${ }^{4}$ and Victória Zeghbi Cochenski Borba ${ }^{*}$
}

\begin{abstract}
Background: Diabetics are at increased risk for impaired mobility and strength, frequently related to the disease control. Sarcopenia is the reduction of muscle mass associated with the decrease in muscle strength and/or performance, resulting in worse morbidity in chronic diseases.

Methods: The objectives of this paper was to assess the prevalence of sarcopenia in patients with type 2 diabetes mellitus (T2DM) and determine its association with diabetes characteristics, progression, and complications, as well as changes in bone mineral density. The sample consisted of patients with T2DM followed at the outpatient clinics of the Serviço de Endocrinologia e Metabologia do Hospital de Clínicas da Universidade Federal do Paraná, from March to August 2016. Participants were men and women above 18 years with T2DM diagnosed at least 1 year earlier. Individuals with chronic diseases, users of any drug that modifies body composition, patients with body mass index (BMI) $>35 \mathrm{or}<18 \mathrm{~kg} / \mathrm{m}^{2}$, and users of illicit drugs or hormonal or nutritional supplementation were excluded. The selected patients answered questionnaires about demographics, eating habits, and disease characteristics, and performed a bone densitometry exam in a dual energy absorptiometry (total body; spine and femur (total and neck)), a handgrip test by manual dynamometer, and an evaluation of the abdominal circumference (AC). The medical records were reviewed seeking diabetes data and laboratory test results. Patients were matched for sex, age, and race with healthy controls [Control Group (CG)]. The diagnosis of sarcopenia was conducted according to the criteria of the Foundation for National Institute of Health.
\end{abstract}

Results: The final sample consisted of 83 patients in the DG and 83 in the CG. The DG had higher BMI, WC, past history of fractures and lower calcium and healthy diet intake $(p<0.005)$, compared to the CG. The DG presented a higher frequency of abnormal BMD (osteopenia in 45 (53\%), and osteoporosis in 14 (19\%)) and comorbidities than the CG $(p<0.005)$. Pre-sarcopenia was not different between groups, but muscle weakness was present in 25 diabetics (18 women) and only in 5 controls ( 4 men) $(p=0.00036)$. Sarcopenia was diagnosed in $13(16.2 \%)$ patients in the DG and $2(2.4 \%)$ in the CG $(p=0.01168)$. Pre-sarcopenia and sarcopenia were associated with altered BMD $(p<0.005)$, with no association with diabetes duration or control. Body mass index and osteoporosis increased the likelihood to have sarcopenia, but hypertension and healthy diet decreased it.

Conclusion: The DG had altered BMD associated with worse glycemic control, and a higher prevalence of sarcopenia, suggesting the need to look for their presence in diabetics.

Keywords: Pre-sarcopenia, Sarcopenia, Type 2 diabetes mellitus, Muscle weakness, DXA

\footnotetext{
*Correspondence: vzcborba@gmail.com

${ }^{4}$ Endocrine Division, Hospital de Clínicas da Universidade Federal do

Paraná (SEMPR), Avenida Agostinho Leão Júnior, 285, Alto da Glória,

Curitiba, PR 80030-110, Brazil

Full list of author information is available at the end of the article
} 


\section{Background}

Diabetes mellitus is a chronic disease characterized by hyperglycemia, caused by defects in the secretion or action of insulin. According to the Brazilian Diabetes Society, there are more than 13 million diabetics in Brazil, equivalent to $6.9 \%$ of the country's population. The global prevalence is estimated at 387 million adults, ages 20-79. More than $90 \%$ of the cases correspond to type 2 diabetes mellitus, characterized by insulin resistance with poor hormone production. Chronic hyperglycemia causes damage to the microcirculation, which impairs the functioning of various organs and tissues and predisposes to chronic complications. These complications are the result of micro- and macrovascular injuries and manifest themselves mainly as retinopathy, nephropathy, neuropathy, peripheral arterial disease, and coronary disease [1].

Damage to the skeletal muscles, with pronounced and accelerated decline in muscle quality, has been described as a new complication of diabetic patients attributed to their longer survival [2]. Sarcopenia in diabetics is associated with higher hospitalization, cardiovascular events, and mortality [3]. Sarcopenia corresponds to a progressive and generalized loss of muscular mass (pre-sarcopenia) concomitant to the decline of muscle performance, also associated with the loss of muscle strength inherent to the aging process [4]. Insulin resistance and oxidative stress are components of the pathophysiological basis of sarcopenia [5-7], which would be related to characteristic components of diabetes, such as vascular alterations [8], chronic inflammation [9], and lipid infiltration in muscles $[10,11]$.

From the age of 40, there is a progressive and generalized physiological loss of muscle mass, estimated at $8 \%$ per decade up to 70 years, and $15-25 \%$ per decade after this age [12]. In Brazil, the prevalence of sarcopenia among individuals over 60 years of age is $16 \%$, corresponding to $20 \%$ of women and $12 \%$ of men [13]. Loss of muscle mass and strength is responsible for reduced mobility and increased incidence of falls and fractures, functional disability, and dependence [3, 14].

The association of diabetes and sarcopenia is described in the literature with prevalence two to three times higher in diabetics than controls $[15,16]$. More important is that sarcopenia is eminently reversible, and it is possible to restore physical capacity through musculoskeletal rehabilitation [17]. Thus, the diagnosis can result in interventions that allow the prevention of lean body deterioration and better quality of life. The high prevalence among diabetic patients makes the screening for sarcopenia from middle age of great value. Improving the prevention and treatment of diabetes in the early stages would help prevent the development of sarcopenia and its complications $[18,19]$.

The objective of this study was to evaluate the prevalence of sarcopenia in patients with type 2 diabetes mellitus (T2DM) and its association with diabetes characteristics, progression, and complications, as well as changes in bone mineral density.

\section{Methods}

This is a cross-sectional study approved by the Ethics Committee of the Hospital das Clínicas da Universidade Federal do Paraná under the number 53569116.7.0000.0096.

\section{Patients}

The sample consisted of T2DM patients followed at the outpatient clinics of the Serviço de Endocrinologia e Metabologia do Hospital de Clínicas da Universidade Federal do Paraná (SEMPR), from March to August of 2016, recruited by convenience during their regular appointment. Participants (diabetes group [DG]) were men and women over 18 years of age, with T2DM diagnosed for at least 1 year, and being treated at SEMPR. Patients with other chronic disease (including type 1 diabetes, any severe or not controlled disease, any infection) users of drugs that directly modify body composition (except diabetes), users of illicit drugs, patients with body mass index (BMI) $>35 \mathrm{~kg} / \mathrm{m}^{2}$ or low weight (BMI $<18 \mathrm{~kg} / \mathrm{m}^{2}$ ), patients taking hormonal or nutritional supplementation, professional athletes and immobilized patients or mobility affected, were excluded. Patients were approached while waiting for their routine appointment at the diabetes outpatient clinic, and after verbal consent, signed the informed consent form.

Data were collected through standardized questionnaires, including demographic data (gender, age, ethnicity [white, black and Asian]); disease characteristics (time since diagnosis, presence of comorbidities, type of complications, type of drug treatment for diabetes [classified as use of one, two, or three oral antidiabetics, combined use of insulin and oral antidiabetics, or isolated insulin use]); eating habits, classified according to World Health Organization (WHO) recommendations in the Food Guide of the Brazilian Population [20], considered insufficient if the number of servings of fruits and vegetables consumed was between 0 and 6 servings per day and sufficient if more than 6 servings per day; calcium intake, estimated by accounting for the approximate amount of calcium present in milk and derivatives, classified as sufficient if daily consumption was greater than $1000 \mathrm{mg}$ for patients aged $19-50$ years and greater than $1200 \mathrm{mg}$ for patients above 50 years. History of traumatic 
or non-traumatic fractures and history of smoking and alcohol intake were also investigated.

After the interview, patients were weighed on a scale $\left(\right.$ Filizola $\left.{ }^{\circledR}\right)$, with precision of $0.1 \mathrm{~kg}$, with capacity of up to $150 \mathrm{~kg}$, wearing light clothes and without shoes; Waist circumference (WC) was measured, using an inextensible tape measure at the level of the umbilical scar; normal values were below $88.0 \mathrm{~cm}$ for women and $102.0 \mathrm{~cm}$ for men, as recommended by the I Brazilian Guideline for Diagnosis and Treatment of Metabolic Syndrome [21]. Stature was measured with a wall stadiometer $\left(\right.$ Tonelli $\left.^{\circledR}\right)$, with precision of $0.1 \mathrm{~cm}$; the subjects were barefoot, standing on a flat surface, with their arms loose along the body, and heels were juxtaposed and leaning against the stem of the stadiometer, head upright and staring ahead [22]. The BMI was calculated and classified as recommended by the WHO [23].

All participants underwent a total body assessment for evaluation of body composition and bone mineral density (BMD) (L1-L4, femoral neck, and total femur) for analysis of bone mass using dual energy X-ray absorptiometry (DXA) on a Lunar Prodigy whole-body scanner (GE Medical Systems, PA+302284, Madison, WI, USA). The software Encore provided data about lean body mass (bone mass plus fat-free mass), bone-free lean mass (lean mass minus fat-free mass), fat mass, and BMD.

The BMD results were expressed as $\mathrm{g} / \mathrm{cm}^{2}$ and evaluated according to the recommendation of the International Society for Clinical Densitometry (ISCD) [24] and Associação Brasileira de Avaliação Óssea e Ósteometabolismo (ABRASSO) [25].

\section{Definition of sarcopenia}

Pre-sarcopenia was defined as a low lean body mass, diagnosed by the criterion of the Foundation for the National Institute of Health (FNIH) as the appendicular lean mass (ALM) divided by the BMI (ALM/BMI); the diagnostic cutoffs are below 0.789 for men and 0.512 for women [26]. Sarcopenia was diagnosed by the concomitance of the decrease in ALM/BMI and the presence of muscle weakness, evaluated through handgrip strength using a Jamar manual dynamometer (Sammons Preston Rolyan, Bolingbrook, IL). An average of three measurements of the dominant arm was analyzed. The cut-off points for the diagnosis of muscle weakness were values lower than $26 \mathrm{~kg}$ for men and less than $16 \mathrm{~kg}$ for women.

A review of the medical records was performed searching for missing data not obtained during the interview, concerning the disease or the laboratory test results The laboratory test were performed in the routine of the clinical pathology laboratory of the Hospital de Clínicas da UFPR and the results closest to the clinical evaluation were captured from the patients files. The methods and reference values for the laboratory test were: fasting glucose (Hexoquinase/G-6-PD, $\mathrm{NV}<100 \mathrm{mg} / \mathrm{dL}$ ); calcium (Arzenazo III, NV=8.5-10.2 mg/dL); creatinine (Jaffé, $\mathrm{NV}=0.8-1.3 \mathrm{mg} /$ day); colorimetric assays for glycated hemoglobin $(\mathrm{NV}<6 \%)$, HDL $(\mathrm{NV}=40-80 \mathrm{mg} / \mathrm{dL})$ and triglycerides $(\mathrm{NV}=50-150 \mathrm{mg} / \mathrm{dL})$; microalbuminuria turbidimetric assay $(\mathrm{NV}<30 \mathrm{mg} / \mathrm{g})$ and LDL estimated by Friedwald equation $(\mathrm{NV}=85-125 \mathrm{mg} / \mathrm{dL})$.

\section{Controls}

The control group (CG) comprised healthy individuals, not athletes, belonging to a database of SEMPR controls, matched for age and sex with the DG. Exclusion criteria were presence of uncontrolled chronic diseases or type 2 diabetes or glucose intolerance, or use of any medication that affects bone metabolism and/or lean mass. Individuals in this group underwent DXA and body composition at SEMPR in the years 2014 and 2015, with the same device as the DG patients and analyzed by the same professional. They answered the same questionnaires and performed the same evaluations as the patients.

\section{Statistical analysis}

Data are presented as mean \pm standard deviation (SD), unless otherwise specified. All statistical analyses were performed with $\mathrm{R}$ software. The normality of the distribution of the variables was evaluated with the Kolmogorov-Smirnov test. The comparison between two groups of quantitative variables was performed with Student's $t$ test for independent samples or using the nonparametric Mann-Whitney test. When comparing more than two groups, we used analysis of variance (ANOVA) with one factor and the least significant difference (LSD) test for multiple comparisons or the nonparametric KruskalWallis test. For the preliminary statistical analysis, we used Fisher's exact test and the Chi square test to assess the association between two qualitative variables. $\mathrm{p}$ values below 0.05 were considered statistically significant.

We performed a univariate analysis and adjusted a logistic regression model considering sarcopenia as the response (dependent) variable and BMI, dyslipidemia, HAS, healthy nutrition, osteoporosis, and past history of fractures as explanatory variables. For each variable and for the presence of the other variable included in the model, we tested the null hypothesis that the probability of sarcopenia was equal for any classification of the variable (lack of association between the variable and sarcopenia), versus the alternative hypothesis of different probabilities. The significance (p) values of the statistical tests and the odds ratio (OR) with a confidence interval of $95 \%$ were calculated. 


\section{Results}

Ninety-six patients were invited to participate in the study during their routine visit to the outpatient clinic. Of these, 90 agreed and signed the informed consent form. Seven patients were excluded because they did not meet the inclusion criteria or did meet one or more of the exclusion criteria. The final sample consisted of 83 patients (59 women), mean age of $65.84 \pm 8.82$ years and mean duration of diabetes of $15.55 \pm 8.67$ years. The CG consisted of 83 apparently healthy individuals (59 women), with mean age of $65.92 \pm 8.84$ years, without serious diseases. Demographic characteristics of the patients and controls are shown in Table 1.

The DG presented higher BMI and WC compared to controls; 65 (78.3\%) patients in the DG were overweight and had a WC above the ideal (60 [72.3\%]). The majority of women evaluated were postmenopausal (58 [98\%]). DG ate less healthy and had an inadequate calcium intake compared to controls.

\section{Past history of fractures}

Previous history of fracture was observed in 32 (38.5\%) patients in the DG. Atraumatic fractures in 32 (88\%) of DG and in $18(21.6 \%)$ of the CG $(\mathrm{p}=0.018)$. The most frequent were ankle (25\%), forearm (20\%), and wrist (20\%). Sixteen patients were under treatment for osteoporosis and the others $(80.7 \%)$ were unaware of the diagnosis.

Table 1 Clinical characteristics of patients and controls

\begin{tabular}{lllc}
\hline & CG & DG & p value \\
\hline Age (years) & $65.92 \pm 8.84$ & $65.84 \pm 8.82$ & 0.9513 \\
Weight (Kg) & $66.09 \pm 9.97$ & $72.32 \pm 12.00$ & \\
Height (m) & $1.59 \pm 0.08$ & $1,6 \pm 0.09$ & \\
BMI (Kg/m²) & $25.96 \pm 2.55^{*}$ & $28.16 \pm 3.89^{*}$ & $<0.0001$ \\
WC (cm) & $86.20 \pm 9.92$ & $96.10 \pm 11.80$ & $<0.0001$ \\
Calcium intake (mg/day) & $680 \pm 425^{*}$ & $400 \pm 304^{*}$ & $<0.0001$ \\
Gender (n (\%)) & & & 1.0 \\
Female & $59(71 \%)$ & $59(71 \%)$ & \\
Male & $24(29 \%)$ & $24(29 \%)$ & \\
Ethnicity & & & \\
White & $81(97.6 \%)$ & $79(95.2 \%)$ & 0.4459 \\
Black & $2(2.4 \%)$ & $4(4.8 \%)$ & \\
Past history of fracture & $18(21 \%)$ & $32(38 \%)$ & 0.018 \\
Current smoking & $1(1.2 \%)$ & $5(6 \%)$ & 0.367 \\
Current alcohol intake & NA & $5(6 \%)$ & - \\
Healthy diet (portions/day) & & & 0.01 \\
0-3 & $23(27 \%)$ & $38(45 \%)$ & \\
4 or more & $60(82 \%)$ & $45(54 \%)$ & \\
\hline
\end{tabular}

Values presented in Mean \pm SD

$K g$ kilograms, $m$ meters, $c m$ centimeters, $n$ number, $W C$ waist circumference, $N A$ not available

* $p<0.05$

\section{Comorbidities and chronic complications}

In the DG, arthrosis (26.5\%), osteoporosis (21.7\%), and depression (13.2\%) were the comorbidities more frequently seen, and in the CG were hypertension (33\%) and dyslipidemia (32\%). The DG presented higher frequency of comorbidities compared to CG as, osteoporosis $(19.3 \%$ vs. $7.8 \%$ ), dyslipidemia (78\% vs. $27 \%)$, systemic arterial hypertension (66\% vs. $28 \%$ ), and hypothyroidism (28\% vs. $11 \%)(\mathrm{p}<0.005$ for all $)$.

Chronic complications of diabetes were present in 51 (61\%) patients; the most prevalent was peripheral neuropathy (31.3\%), cardiovascular disease (28.9\%), and retinopathy $(27.7 \%)$. The treatment varied between the use of one or more oral hypoglycemic agents combined or not, with insulin. The great majority of patients (82.1\%) used one or more oral drugs (metformin and/or sulfonylurea), and 15 (17.9\%) used only insulin (Table 2).

\section{Laboratory tests}

The mean laboratory results for the DG were as follows: fasting glucose $166.4 \pm 68.1 \mathrm{mg} / \mathrm{dL}(\mathrm{NV}<110 \mathrm{mg} /$ $\mathrm{dL})$; glycated hemoglobin $8.08 \pm 1.85 \%(\mathrm{NV}<6 \%)$; serum creatinine $1.16 \pm 0.85 \mathrm{mg} / \mathrm{dL} \quad(\mathrm{NV}=0.8-1.3 \mathrm{mg} / \mathrm{dL})$; LDL $103.70 \pm 39.30 \mathrm{mg} / \mathrm{dL}(\mathrm{NV}=85-125 \mathrm{mg} / \mathrm{dL})$; HDL $45.56 \pm 28.71 \mathrm{mg} / \mathrm{dL} \quad(\mathrm{NV}=40-80 \mathrm{mg} /$ day $)$; triglycerides $147.0 \pm 76.4 \quad(\mathrm{NV}=50-150 \mathrm{mg} / \mathrm{dL}) ;$ microalbuminuria $32.3 \pm 50.8 \mathrm{mg} / \mathrm{g}(\mathrm{NV}<30 \mathrm{mg} / \mathrm{g})$; and calcium $9.56 \pm 0.55 \mathrm{mg} / \mathrm{dL} \quad(\mathrm{NV}=8.5-10.2 \mathrm{mg} / \mathrm{dL})$. Controls had lower levels of fasting glucose $93.33 \pm 19.91 \mathrm{mg} / \mathrm{dL}$

Table 2 Medications used and chronic complications in the DG

\begin{tabular}{lll}
\hline $\begin{array}{l}\text { Chronic complica- } \\
\text { tions }\end{array}$ & $\begin{array}{l}\text { DG absolute fre- } \\
\text { quency }\end{array}$ & $\begin{array}{l}\text { DG relative frequency } \\
\text { (\%) }\end{array}$ \\
\hline Peripheral neuropathy & 26 & 31.32 \\
Cardiovascular & 24 & 28.91 \\
Retinopathy & 23 & 27.71 \\
Renal & 20 & 24.09 \\
Cataract & 15 & 18.07 \\
Medications & & \\
$\begin{array}{l}\text { Anti-diabetic } \\
\text { 1 oral hypoglycemic } \\
\quad \text { agent }\end{array}$ & 15 & 18.07 \\
2 oral hypoglycemic & 8 & \\
$\quad$ agents & & 9.6 \\
Oral hypoglyce- & 45 & \\
$\quad$ mic+ Insulin & & 54.21 \\
Insulin only & 15 & 18.07 \\
$\quad$ Metformin & 70 & 84.33 \\
Cholesterol lowering & & 80.72 \\
$\quad$ Simvastatin & 67 &
\end{tabular}

Oral hypoglycemic agent $=$ metformin and/or sulfonylurea $\%$ Percentage 
$(\mathrm{p}<0.001)$; calcium $9.34 \pm 0.48 \mathrm{mg} / \mathrm{dL}(\mathrm{p}=0.007)$; and creatinine $0.91 \pm 0.2 \mathrm{mg} / \mathrm{dL}(\mathrm{p}=0.006)$.

\section{BMD results}

The average BMD $\left(\mathrm{g} / \mathrm{cm}^{2}\right)$ in the DG was L1-L4 $1.125 \pm 0.214$; femoral neck $0.863 \pm 0.168$, and total femur $0.960 \pm 0.214$. Altered BMD was present in $59(71 \%)$ patients; 45 (53\%) had osteopenia and $14(19 \%)$ osteoporosis. In the CG the average BMD $\left(\mathrm{g} / \mathrm{cm}^{2}\right)$ was $\mathrm{L} 1-$ L4 $1.098 \pm 0.23(\mathrm{p}=0.197)$; femoral neck $0.865 \pm 0.228$ $(\mathrm{p}=0.221)$; and total femur $0.938 \pm 0.159(\mathrm{p}=0.306) ; 48$ controls (57\%) had altered BMD.

In the DG the diagnosis of altered BMD was associated with past history of fractures $(\mathrm{p}=0.053)$; female sex $(\mathrm{p}=0.032)$; lower BMI $(\mathrm{p}<0.001)$; abnormal WC $(\mathrm{p}<0.001)$; and higher glycated hemoglobin $(\mathrm{HA1C})$ $(\mathrm{p}<0.001)$.

\section{Diagnosis of pre-sarcopenia and sarcopenia}

The mean ALM/BMI in the DG was $0.848 \pm 0.234$ in males and $0.603 \pm 0.225$ in females, while in the CG the mean value was $0.813 \pm 0.405$ in males $(\mathrm{p}=0.297)$ and $0.621 \pm 0.382$ in females $(p=0.082)$. Considering the respective cut-off values for sex, pre-sarcopenia was present in $18(21 \%)$ diabetic patients and 21 (25\%) controls $(\mathrm{p}=0.582)$. Patients with pre-sarcopenia had a tendency to have an altered BMD $(\mathrm{p}=0.054)$ and more frequently had lower BMI $(p=0.024)$, osteoporosis $(p=0.053)$, past history of fractures $(\mathrm{p}=0.003)$, weak grip strength $(\mathrm{p}<0.001)$, and an unhealthy diet $(\mathrm{p}=0.017)$.

The DG presented lower muscle strength than the CG identified in 25 diabetics (18 women) and in 5 controls $(4 \mathrm{men})(\mathrm{p}<0.001)$. The mean grip strength in the DG was $18.4 \pm 5.16$ and $29.39 \pm 6.37 \mathrm{~kg}$ in women and men, respectively, and in the control group the mean value among women was $26 \pm 16.45 \mathrm{~kg}(\mathrm{p}<0.001)$ and $33.92 \pm 18.25 \mathrm{~kg}$ among men $(\mathrm{p}=0.20)$.

Sarcopenia was identified in 13 (15.6\%) diabetics and in $2(2.4 \%)$ controls $(\mathrm{p}=0.012)$ (Fig. 1 ).

An association was observed between sarcopenia and osteoporosis $(\mathrm{p}<0.001)$, and dyslipidemia $(\mathrm{p}=0.005)$; and between pre-sarcopenia and history of fractures $(\mathrm{p}=0.029)$. But no association was found between glycemic controls (glycated hemoglobin), chronic complications of diabetes and sarcopenia $(\mathrm{p}>0.05)$ ).

The variables BMI, WC, calcium intake, dyslipidemia, hypertension, hypothyroidism, other comorbidities, unhealthy diet $(<3$ healthy portions/day), osteoporosis, and past history of fractures were associated with the diagnosis of pre-sarcopenia or sarcopenia,

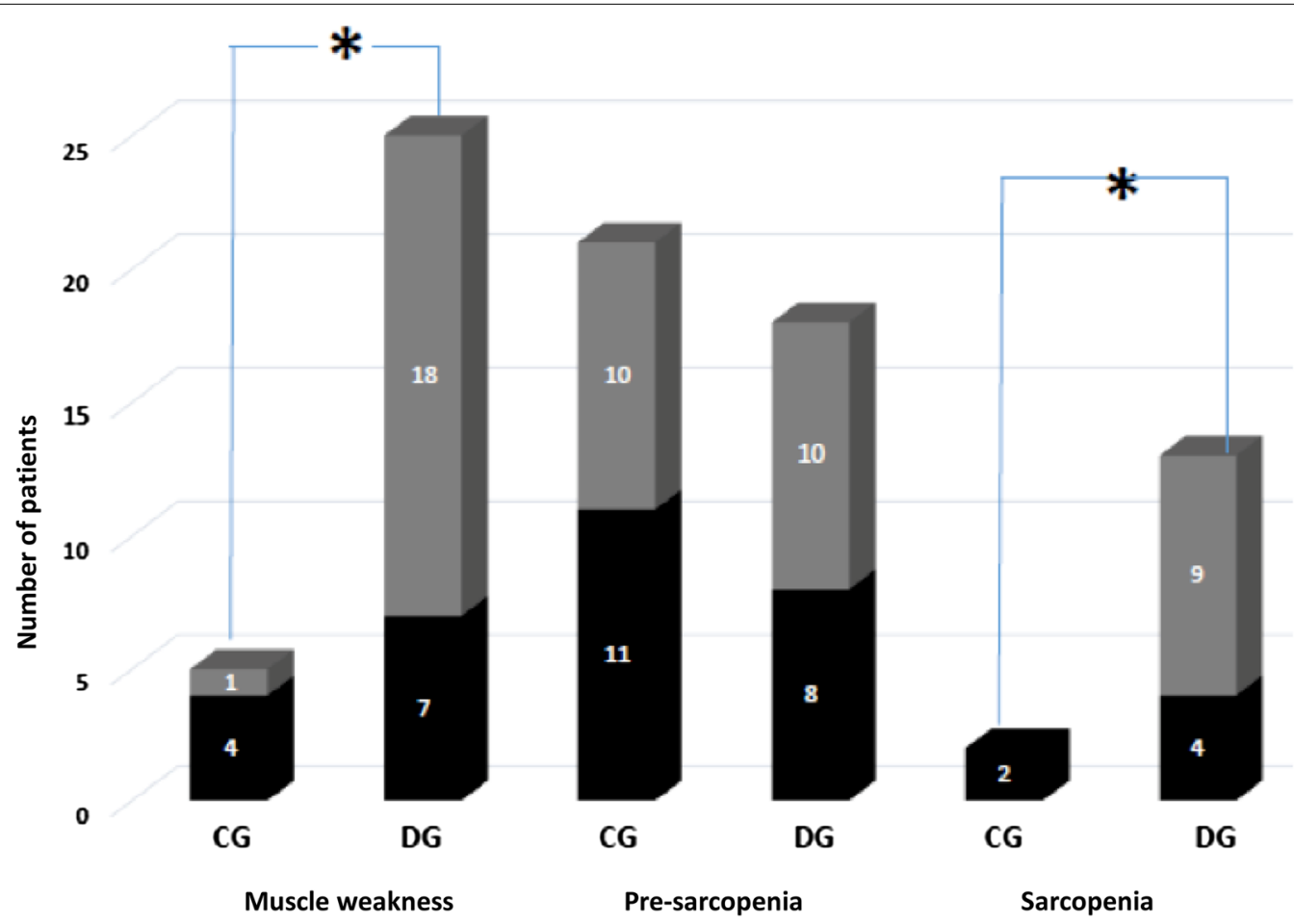

Fig. 1 Prevalence of muscle weakness, pre-sarcopenia and sarcopenia. ${ }^{*} \mathrm{p}<0.005$-Fisher's exact and Chi square tests; CG control group, DG diabetic group 
and were tested in an univariate linear regression analysis as possible explanatory variables for the diagnosis of sarcopenia. Only dyslipidemia $(p=0.020)$, unhealthy diet $(p=0.016)$, osteoporosis $(p=0.016)$, and past history of fractures were significant. A multivariate analysis with a stepwise method to select the best regression equation was performed using the significant variables plus hypertension $(\mathrm{p}=0.059)$, past history of fractures $(\mathrm{p}=0.063)$, and BMI $(\mathrm{p}=0.083)$. The results showed that BMI OR $=1.4272($ CI 25\%-95\% 1.280-1.9661) and the presence of osteoporosis OR $=11.9742$ (CI 25\%-95\% 2.0514-109.0409) increased the likelihood to have sarcopenia, but the presence of hypertension OR $=1.1250$ (CI $25 \%-95 \% 0.0169-0.7306$ ) and healthy diet $\mathrm{OR}=0.0584$ (CI 25\%-95\% 0.0045-0.3465) decreased it (Fig. 2).

\section{Discussion}

This study evaluated in an unprecedented way the BMD, lean mass, and muscular strength of patients with type 2 diabetes mellitus from a tertiary care outpatient clinic. A higher prevalence of muscle weakness, sarcopenia, and low bone mass was observed in these patients.

Anthropometric evaluation showed that the DG had a higher BMI and waist circumference compared to controls, with $78.3 \%$ being overweight and $72.3 \%$ with waist circumference above normal, indicating high rates of overweight and obesity. Sarcopenia and central obesity (present in the metabolic syndrome, which also exhibits insulin resistance) are frequently combined conditions in elderly individuals [27]. Together, aging and obesity are associated with progressive deterioration of muscle quality. In addition to being an important risk factor for frailty, obesity also increases the levels of inflammatory markers that inhibit the synthesis of muscle proteins [26]. The association found between pre-sarcopenia and high body mass index is also described in other studies [28, 29].

The literature describes a process named diabetic paradox, which is the normal BMD and increased risk of fractures in diabetics [28]. The genesis may involve direct or indirect effects of glycaemia on bone cells, hypovitaminosis D, hormonal factors, and obesity [29]. Although the literature does not consider DM2 a risk factor for osteoporosis or metabolic bone disease [30], DM2 patients in this study presented BMD alterations in $71 \%$, osteoporosis in $19 \%$, and a tendency to associate BMD with the past history of fractures. Another important finding was the association between altered BMD with worse glycemic control, measured by glycated hemoglobin levels, an index of the diabetes severity, already suggested by others [30-32].

Muscle performance evaluated by dynamometry showed a five times higher muscle weakness among diabetics, indirectly suggesting a greater impairment of muscle quality. Sarcopenia was diagnosed in $16 \%$ of the DG, eight times more prevalent than in the GC. The main mechanisms proposed to explain the greater susceptibility of diabetics to muscle mass deterioration are related to the pathogenesis of sarcopenia, such as reduction in the synthesis or sensitivity of anabolic hormones [5], cytokine secretion, chronic inflammatory state, and induced mitochondrial dysfunction by chronic hyperglycemia [19].

Patients with sarcopenia have higher rates of falls and fractures [33]. In this study, there was a relationship between pre-sarcopenia with a history of fractures and

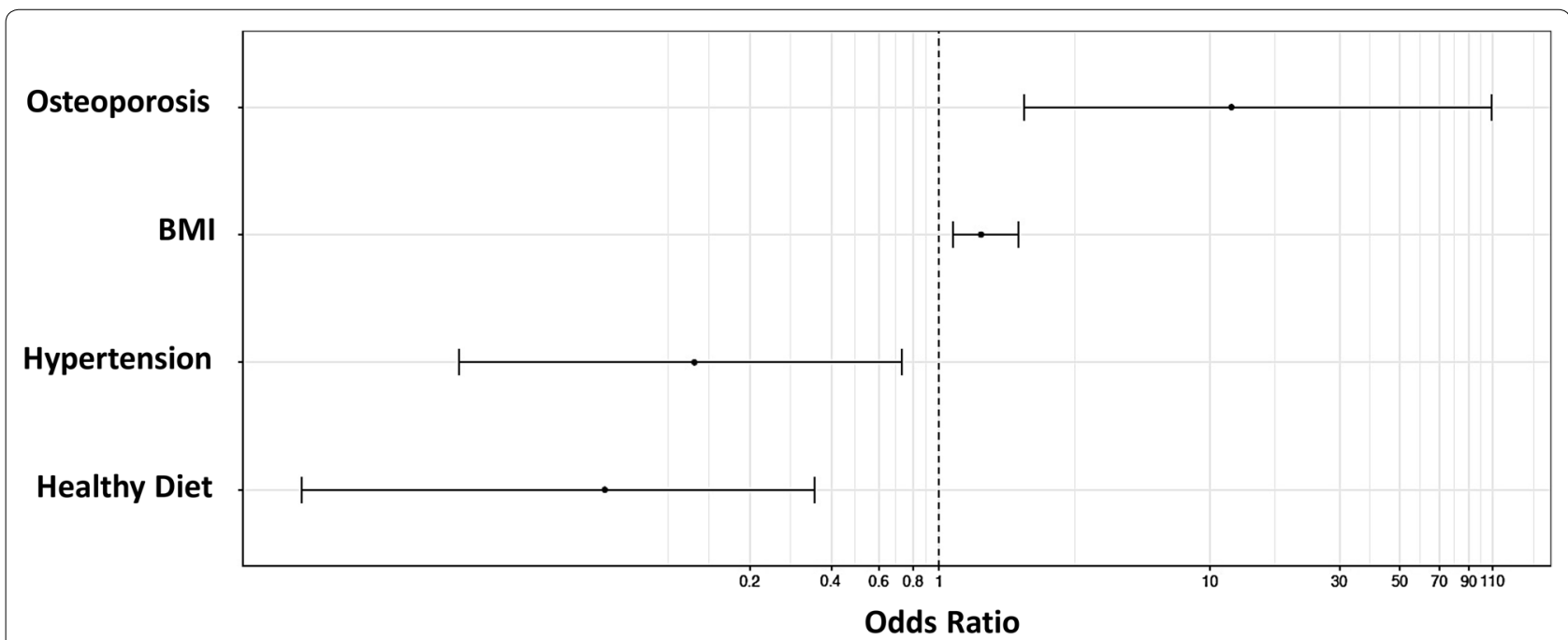

Fig. 2 Multivariate analyses of the factors that influenced the diagnosis of sarcopenia. BMI Body mass index $\left(\mathrm{Kg} / \mathrm{m}^{2}\right)$ 
association with low BMD, suggesting that body composition and muscle function may play a synergistic role in the mechanism of falls and fractures in patients with diabetes. The association between sarcopenia and altered $\mathrm{BMI}$ is an aggravating factor for the morbidity of the condition. Lower muscle strength and poor ability in physical performance tests are risk factors for falls [30], and the risk of fractures is even greater in patients with compromised bone quality.

Diabetics had poorer eating habits than controls. Calcium intake was 3.5 times lower in the diabetic group. Consumption of milk and dairy products is associated with a reduction in risk of developing diabetes [34], glucose regulation, and better diabetes management [35, 36]. Frequent consumption of fruits and vegetables helps prevent the development of sarcopenia in the elderly [37, 38]. In this study, patients who ate less healthy food had more pre-sarcopenia. Oxidative stress is considered one of the main pathogenetic mechanisms of sarcopenia. A diet rich in fruits and vegetables could provide antioxidants and reduce the damage caused by the inflammatory status, reducing the risk of developing the disease [38].

Comorbidities are very common in diabetic patients. Dyslipidemia is one of the most common comorbidities related to T2DM $[39,40]$ and was observed in $94 \%$ of the DG. This massive prevalence increases the risk of cardiovascular disease and premature death. An association between sarcopenia and dyslipidemia was found, a result consistent with studies that verified the influence of obesity and sarcopenia on worsening dyslipidemia $[40,42]$. Systemic arterial hypertension is twice as prevalent in diabetics compared to the general population and is present in $50 \%$ of patients at the time of diagnosis of T2DM [41-43]. A higher prevalence of $79.5 \%$ of hypertension was observed in the GD, more than double that observed in controls. On the other hand, the presence of hypertension in this specific population decreased the possibility of sarcopenia, consistent with the suggestion that not the disease but its treatment with beta-blockers or reninangiotensin aldosterone inhibitors could prevent muscle wasting [44, 45].

Hypothyroidism, present in $33.7 \%$ of the GD, was much more frequent in this group than in the CG. Diabetics are more likely to have hypothyroidism when compared to the healthy population $[46,47]$. Hypothyroidism also aggravates the complications of diabetes, such as peripheral arterial disease, nephropathy, retinopathy, diabetic neuropathy [46], and metabolic disorders, such as dyslipidemia, which may contribute to high mortality due to ischemic cardiovascular disease in T2DM [48].

Diagnosis of pre-sarcopenia (decrease in lean mass) was similar between the groups, suggesting that in this population, the quantitative analysis of muscle mass alone is not a good marker of muscle quality. Although muscle mass is a contributory factor for muscle strength, evidence shows that muscle performance is more related to the muscle function [49].

Deterioration of lean mass and muscle function was clearly more pronounced among diabetic patients compared to controls, although it was not possible to establish a relationship between sarcopenia and diabetes performance, evaluated by diabetes duration, glycemic control, and presence of chronic complications. Similarly, the literature has shown that the greatest decline in muscle mass and function among elderly patients with T2DM occurs independently of disease duration, metabolic control, and the presence of chronic complications [48]. However, other studies defend the relevance of this association [5, 50-52].

In the DG the diagnosis of altered BMD was associated with past history of fractures $(p=0.053)$; female sex $(p=0.032)$; lower BMI $(p=0.0076)$; abnormal WC $(\mathrm{p}=0.00027)$; and higher glycated hemoglobin (HA1C) $(\mathrm{p}<0.0001)$.

Although similar in the DG and CG, BMD in the DG was associated with traditional risk factors such as past history of fractures, female sex, and lower BMI and specific for this population with worse glycemic control and abnormal WC, which points to the need to evaluate the risk factors for fracture and perform densitometric evaluation in these patients. The impact of pre-sarcopenia evaluation still needs to be better determined; however, higher prevalence of sarcopenia suggests the importance of the evaluation of muscular function through dynamic tests such as a simple measurement of handgrip by dynamometry. The early diagnosis of both diseases would enable preventive measures to increase strength and prevent falls and fractures, which would have an impact on the quality of life and morbidity of diabetic patients.

The limitations of this study were the lack of the performance evaluation and the absence of a healthy population without abnormal glucose metabolism with similar BMI (30 and $35 \mathrm{~kg} / \mathrm{m}^{2}$ ) to compare groups with the same body composition.

In conclusion, this population of T2DM had higher prevalence of sarcopenia than a non-diabetic population. Muscle involvement occurred in varying degrees, regardless of the characteristics of the diabetes. The recognition of individuals at risk could urge preventive measures and treatment by the primary care provider to prevent lean mass deterioration and promote better quality of life for patients with type 2 diabetes mellitus.

\section{Abbreviations}

T2DM: type 2 diabetes mellitus; SEMPR: Serviço de Endocrinologia e Metabologia do Hospital de Clínicas da Universidade Federal do Paraná; BMI: body 
mass index; DXA: dual energy absorptiometry; AC: abdominal circumference; CG: control group; FNIH: Foundation for National Institute of Health; DG: diabetes group; BMD: bone mineral density; ISCD: International Society for Clinical Densitometry; ABRASSO: Associação Brasileira de Avaliação Óssea e Ósteometabolismo; FNIH: Foundation for the National Institute of Health; ALM: appendicular lean mass; SD: standard deviation; ANOVA: analysis of variance; LSD: least significant difference; OR: odds ratio; Kg: kilograms; M: meters; Cm: centimeters; N: number; WC: waist circumference; NA: not available; \%: percentage; NV: normal values; HA1C: glycated hemoglobin.

\section{Authors' contributions}

HT collected, analyzed and interpreted the patient data, wrote the manuscript; GK collected, analyzed and interpreted the patient data, wrote the manuscript: $\mathrm{THJ}$ collected the control group data; RRP did all the statistical analysis; CAM contributed to the paper writing corrections; VZCB conceived the study, corrected the paper and was a major contributor in writing the manuscript. All authors read and approved the final manuscript.

\section{Author details}

${ }^{1}$ Universidade Federal do Paraná, Curitiba, PR, Brazil. ${ }^{2}$ Internal Medicine, Universidade Federal do Paraná, Curitiba, PR, Brazil. ${ }^{3}$ Statistics Department, Universidade Federal do Paraná, Curitiba, PR, Brazil. ${ }^{4}$ Endocrine Division, Hospital de Clínicas da Universidade Federal do Paraná (SEMPR), Avenida Agostinho Leão Júnior, 285, Alto da Glória, Curitiba, PR 80030-110, Brazil.

\section{Competing interests}

The authors Gabrielle Kisielewicz, Heloísa Trierweiler, Thaísa Hoffmann Jonasson, Ricardo Rasmussen Petterle, Victória Zeghbi Cochenski Borba, declare that they have no conflict of interest.

\section{Availability of data and materials}

The datasets used and/or analyzed during the current study are available from the corresponding author on reasonable request.

\section{Consent for publication}

Not applicable. No individual information is present in the paper.

\section{Ethics approval and consent to participate}

This study was approved by the Ethics Committee of the Hospital das Clínicas da Universidade Federal do Paraná under the Number 53569116.7.0000.0096.

\section{Funding}

No funding or financial support was received.

\section{Publisher's Note}

Springer Nature remains neutral with regard to jurisdictional claims in published maps and institutional affiliations.

Received: 3 March 2018 Accepted: 20 March 2018

Published online: 03 April 2018

\section{References}

1. Bertoluci MC, Moreira RO, Faludi A, Izar MC, Schaan BD, Valerio CM, Bertolami MC, Chacra AP, Malachias MVB, Vencio S, Saraiva JFK, Betti R, Turatti L, Fonseca FAH, Bianco HT, Sulzbach M, Bertolami A, Salles JEN, Hohl A, Trujilho F, Lima EG, Miname MH, Zanella MT, Lamounier R, Sá JR, Amodeo C, Pires AC, Santos RD. Brazilian guidelines on prevention of cardiovascular disease in patients with diabetes: a position statement from the Brazilian Diabetes Society (SBD), the Brazilian Cardiology Society (SBC) and the Brazilian Endocrinology and Metabolism Society (SBEM). Diabetol Metab Syndr. 2017;9:1-36. https://doi.org/10.1186/s13098-017-0251-z.

2. Liccini A, Malmstrom TK. Frailty and sarcopenia as predictors of adverse health outcomes in persons with diabetes mellitus. J Am Med Dir Assoc. 2016;17:846-51. https://doi.org/10.1016/j.jamda.2016.07.007.

3. Hamasaki H, Kawashima Y, Katsuyama H, Sako A, Goto A, Yanai H. Association of handgrip strength with hospitalization, cardiovascular events, and mortality in Japanese patients with type 2 diabetes. Sci Rep. 2017;7:1-9. https://doi.org/10.1038/s41598-017-07438-8.

4. Cruz-Jentoft AJ, Baeyens JP, Bauer JM, Boirie Y, Cederholm T, Landi F, Martin FC, Michel JP, Rolland Y, Schneider SM, Topinková E, Vandewoude M, Zamboni M. Sarcopenia: European consensus on definition and diagnosis. Age Ageing. 2010;39:412-23. https://doi.org/10.1093/ageing/ afq034.

5. Kim TN, Choi KM. Sarcopenia: definition, epidemiology, and pathophysiology. J Bone Metab. 2013;20:1-10. https://doi.org/10.11005/jbm.20.1.1.

6. Khamseh ME, Malek M, Aghili R, Emami Z. Sarcopenia and diabetes: pathogenesis and consequences. Br J Diabetes Vasc Dis. 2011;11:230-4. https://doi.org/10.1177/1474651411413644.

7. Morley JE, Malmstrom TK, Rodriguez-Mañas L, Sinclair AJ. Frailty, sarcopenia and diabetes. J Am Med Dir Assoc. 2014;15(12):853-9. https://doi. org/10.1016/j.jamda.2014.10.001.

8. Abbatecola AM, Olivieri F, Corsonello A, Strollo F, Fumagalli A, Lattanzio F. Frailty and safety: the example of diabetes. Drug Saf. 2012;35:63-71. https://doi.org/10.1007/BF03319104.

9. Pedersen M, Bruunsgaard H, Weis N, Hendel HW, Andreassen BU, Eldrup E, Dela F, Pedersen BK. Circulating levels of TNF-alpha and IL-6-relation to truncal fat mass and muscle mass in healthy elderly individuals and in patients with type-2 diabetes. Mech Ageing Dev. 2003;124:495-502. https://doi.org/10.1016/S0047-6374(03)00027-7.

10. Delmonico MJ, Harris TB, Visser M, Park SW, Conroy MB, VelasquezMieyer P, Boudreau R, Manini TM, Nevitt M, Newman AB, Goodpaster $\mathrm{BH}$. Longitudinal study of muscle strength, quality, and adipose tissue infiltration. Am J Clin Nutr. 2009;90:1579-85. https://doi.org/10.3945/ ajen.2009.28047.INTRODUCTION.

11. Song MY, Ruts E, Kim J, Janumala I, Heymsfield S, Gallagher D. Sarcopenia and increased adipose tissue infiltration of muscle in elderly African American women. Am J Clin Nutr. 2004;79:874-80.

12. Filippin LI, de Oliveira Teixeira VN, da Silva MPM, Miraglia F, da Silva FS. Sarcopenia: a predictor of mortality and the need for early diagnosis and intervention. Aging Clin Exp Res. 2015;27:249-54. https://doi. org/10.1007/s40520-014-0281-4.

13. Diz JBM, Leopoldino AAO, Moreira BDS, Henschke N, Dias RC, Pereira LSM, Oliveira VC. Prevalence of sarcopenia in older Brazilians: a systematic review and meta-analysis. Geriatr Gerontol Int. 2017;17:5-16. https://doi. org/10.1111/ggi.12720.

14. Schaap LA, van Schoor NM, Lips P, Visser M. Associations of sarcopenia definitions, and their components, with the incidence of recurrent falling and fractures; the Longitudinal Aging Study Amsterdam. J Gerontol Ser A. 2017, 1-6. https://doi.org/10.1093/gerona/glx245.

15. Park S, Goodpaster B, Strotmeyer E, Kuller L, Broudeau R, Kammerer C, De Rekeneire N, Harris T, Schwartz A, Tylavsky F, Cho Y, Newman A. Accelerated loss of skeletal muscle strength in older adults with type 2 diabetes the health, aging, and body composition study. Diabetes Care. 2007;30:1507-12. https://doi.org/10.2337/dc06-2537.Additional.

16. Koo BK, Roh E, Yang YS, Moon MK. Difference between old and young adults in contribution of $\beta$-cell function and sarcopenia in developing diabetes mellitus. J. Diabetes Investig. 2016;7:233-40. https://doi. org/10.1111/jdi.12392.

17. Ng TP, Feng L, Nyunt MSZ, Feng L, Niti M, Tan BY, Chan G, Khoo SA, Chan SM, Yap P, Yap KB. Nutritional, physical, cognitive, and combination interventions and frailty reversal among older adults: a randomized controlled trial. Am J Med. 2015;128:1225-36. https://doi.org/10.1016/j. amjmed.2015.06.017.

18. Umegaki H. Sarcopenia and diabetes: hyperglycemia is a risk factor for age-associated muscle mass and functional reduction. J Diabetes Investig. 2015;6:623-4. https://doi.org/10.1111/jdi.12365.

19. Landi F, Onder G, Bernabei R. Sarcopenia and diabetes: two sides of the same coin. J Am Med Dir Assoc. 2013;14(8):540-1. https://doi. org/10.1016/j.jamda.2013.05.004.

20. Brasil, Guia alimentar para a população brasileira, 2008. ISBN: 978-85-334-2176-9.

21. Sociedade Brasileira de Cardiologia. I Diretriz Brasileira de Diagnóstico e Tratamento da Síndrome Metabólica. Arq Bras Cardiol. 2005;84:4-28. https://doi.org/10.1590/S0066-782X2005000700001.

22. Anthropometry procedures manual, Nhanes. 3 (2017-2018) 6-10. 
23. World Health Organisation. Obesity: preventing and managing the global epidemic. Report of a WHO Consultation. Geneva: World Health Organisation; 2004.

24. Shepherd JA, Schousboe JT, Broy SB, Engelke K, Leslie WD. Executive summary of the 2015 ISCD position development conference on advanced measures from DXA and QCT: fracture prediction beyond BMD. J Clin Densitom. 2015;18:274-86. https://doi.org/10.1016/j.jocd.2015.06.013.

25. Brandao CM, Camargos BM, Zerbini CA, Plapler PG, Mendonça LM, Albergaria BH, Pinheiro MD, Prado MD, Eis SR. Posições oficiais 2008 da Sociedade Brasileira de Densitometria Clínica (SBDens). Arq Bras Endocrinol Metabol. 2009;53:107-12. https://doi.org/10.1590/ s0004-27302009000100016.

26. Studenski SA, Peters KW, Alley DE, Cawthon PM, McLean RR, Harris TB, Ferrucci L, Guralnik JM, Fragala MS, Kenny AM, Kiel DP, Kritchevsky SB, Shardell MD, Dam TTL, Vassileva MT. The FNIH sarcopenia project: rationale, study description, conference recommendations, and final estimates. J Gerontol Ser A Biol Sci Med Sci. 2014;69:547-58. https://doi.org/10.1093/ gerona/glu010.

27. An KO, Kim J. Association of sarcopenia and obesity with multimorbidity in Korean adults: a Nationwide Cross-Sectional Study. J Am Med Dir Assoc. 2016;17:960.e1-960.e7. https://doi.org/10.1016/j. jamda.2016.07.005

28. Tarantino U, Baldi J, Scimeca M, Piccirilli E, Piccioli A, Bonanno E, Gasbarra E. The role of sarcopenia with and without fracture. Injury. 2016;47:S3-10. https://doi.org/10.1016/j.injury.2016.07.057.

29. Molino S, Dossena M, Buonocore D, Verri M. Sarcopenic obesity: an appraisal of the current status of knowledge and management in elderly people. J Nutr Health Aging. 2016;20:780-8. https://doi.org/10.1007/ s12603-015-0631-8.

30. Martínez SB, Cenarruzabeitia NV, San Martin JE, Canelas AC. La paradoja diabética: densidad mineral ósea y fractura en la diabetes tipo 2. Endocrinol Y Nutr. 2016;63:495-501. https://doi.org/10.1016/j. endonu.2016.06.004.

31. Walsh JS, Vilaca T. Obesity, type 2 diabetes and bone in adults. Calcif Tissue Int. 2017;100:528-35. https://doi.org/10.1007/s00223-016-0229-0.

32. Napoli N, Chandran M, Pierroz DD, Abrahamsen B, Schwartz AV, Ferrari SL. Mechanisms of diabetes mellitus-induced bone fragility. Nat Rev Endocrinol. 2017;13:208-19. https://doi.org/10.1038/nrendo.2016.153.

33. Scott D, Seibel M, Cumming R, Naganathan V, Blyth F, Le Couteur DG, Handelsman DJ, Waite LM, Hirani V. Sarcopenic obesity and its temporal associations with changes in bone mineral density, incident falls, and fractures in older men: the concord health and ageing in men project. J Bone Miner Res. 2017;32:575-83. https://doi.org/10.1002/jbmr.3016.

34. Moslehi N, Shab-Bidar S, Mirmiran P, Sadeghi M, Azizi F. Associations between dairy products consumption and risk of type 2 diabetes: Tehran lipid and glucose study. Int J Food Sci Nutr. 2015;66:692-9. https://doi.org /10.3109/09637486.2015.1034249

35. Pasin G, Comerford KB. Dairy foods and dairy proteins in the management of type 2 diabetes: a systematic review of the clinical evidence. Adv Nutr. 2015;6:245-59. https://doi.org/10.3945/an.114.007690.to.

36. Aune $D$, Norat T, Romundstad P, Vatten LJ. Dairy products and the risk of type 2 diabetes: a systematic review and dose-response meta-analysis of cohort studies. Am J Clin Nutr. 2013;98:1066-83. https://doi.org/10.3945/ ajcn.113.059030.INTRODUCTION.

37. Kim J, Lee Y, Kye S, Chung YS, Kim KM. Association of vegetables and fruits consumption with sarcopenia in older adults: the fourth Korea national health and nutrition examination survey. Age Ageing. 2015;44:96-102. https://doi.org/10.1093/ageing/afu028.

38. Chan R, Leung J, Woo J. A prospective cohort study to examine the association between dietary patterns and sarcopenia in Chinese community-dwelling older people in Hong Kong. J Am Med Dir Assoc. 2016;17:336-42. https://doi.org/10.1016/j.jamda.2015.12.004.
39. Masahhit M, Husain H, Samir R. Pattern of dyslipidemia in type 2 diabetic patients in Fayoum (Egypt). Asian J Med Health. 2017;8:1-12. https://doi. org/10.9734/AJMAH/2017/36088.

40. Daya R, Bayat Z, Raal F. Prevalence and pattern of dyslipidaemia in type 2 diabetes mellitus patients at a tertiary care hospital. J Endocrinol Metab Diabetes S Afr. 2017;22:31-5. https://doi.org/10.1080/16089677.2017.136 0064.

41. Baek SJ, Nam GE, Han KD, Choi SW, Jung SW, Bok AR, Kim YH, Lee KS, Han BD, Kim DH. Sarcopenia and sarcopenic obesity and their association with dyslipidemia in Korean elderly men: the 2008-2010 Korea National Health and Nutrition Examination Survey. J Endocrinol Investig. 2014;37:247-60. https://doi.org/10.1007/s40618-013-0011-3.

42. Sanada K, lemitsu M, Murakami H, Gando Y, Kawano H, Kawakami R, Tabata I, Miyachi M. Adverse effects of coexistence of sarcopenia and metabolic syndrome in Japanese women. Eur J Clin Nutr. 2012;66:1093-8. https://doi.org/10.1038/ejcn.2012.43.

43. Scheen AJ. Effects of reducing blood pressure on cardiovascular outcomes and mortality in patients with type 2 diabetes: focus on SGLT2 inhibitors and EMPA-REG OUTCOME. Diabetes Res Clin Pract. 2016:121:204-14. https://doi.org/10.1016/.diabres.2016.09.016.

44. Oktay AA, Akturk HK, Jahangir E. Diabetes mellitus and hypertension: a dual threat. Curr Opin Cardiol. 2016;31:402-9. https://doi.org/10.1097/ HCO.0000000000000297.

45. Collamati A, Marzetti E, Calvani R, Tosato M, D'Angelo E, Sisto AN, Landi F. Sarcopenia in heart failure: mechanisms and therapeutic strategies. J Geriatr Cardiol. 2016;13:615-24. https://doi.org/10.11909/j. issn.1671-5411.2016.07.004

46. Han C, He X, Xia X, Li Y, Shi X, Shan Z, Teng W, Veves A. Subclinical hypothyroidism and type 2 diabetes: a systematic review and meta-analysis. PLoS One. 2015;10:1-22. https://doi.org/10.1371/journal.pone.0135233.

47. Moura Neto A, Parisi MCR, Alegre SM, Pavin EJ, Tambascia MA, ZantutWittmann DE. Relation of thyroid hormone abnormalities with subclinical inflammatory activity in patients with type 1 and type 2 diabetes mellitus. Endocrine. 2016;51:63-71. https://doi.org/10.1007/s12020-015-0651-5.

48. Katyayini R, Benglorkar VM. Cross-sectional study of dyslipidemia in type 2 diabetes mellitus patients with and without associated hypothyroidism. J Assoc Physicians India. 2016;64:38-9.

49. Fragala MS, Kenny AM, Kuchel GA. Muscle quality in aging: a multidimensional approach to muscle functioning with applications for treatment. Sports Med. 2015;45:641-58. https://doi.org/10.1007/ s40279-015-0305-z.

50. Guerrero N, Bunout D, Hirsch S, Barrera G, Leiva L, Henríquez S, De la Maza MP. Premature loss of muscle mass and function in type 2 diabetes. Diabetes Res Clin Pract. 2016;117:32-8. https://doi.org/10.1016/j. diabres.2016.04.011.

51. Yang R, Zhang Y, Shen X, Yan S. Sarcopenia associated with renal function in the patients with type 2 diabetes. Diabetes Res Clin Pract. 2016;118:121-9. https://doi.org/10.1016/j.diabres.2016.06.023.

52. Guillet $C$, Boirie Y. Insulin resistance: a contributing factor to age-related muscle mass loss. Diabetes Metab. 2005;31:20-6. https://doi.org/10.1016/ s1262-3636(05)73648-x.

\section{Submit your next manuscript to BioMed Central and we will help you at every step:}

- We accept pre-submission inquiries

- Our selector tool helps you to find the most relevant journal

- We provide round the clock customer support

- Convenient online submission

- Thorough peer review

- Inclusion in PubMed and all major indexing services

- Maximum visibility for your research

Submit your manuscript at www.biomedcentral.com/submit 